\title{
Osteopontin is not Critical for Otoconia Formation or Balance Function
}

\author{
Xing ZhaO ${ }^{1}$, Sherri M. Jones ${ }^{2}$, Wallace B. Thoreson $^{3}$, and Yunxia Wang Lundberg ${ }^{1}$ \\ ${ }^{1}$ Genetics Department, Boys Town National Research Hospital, Omaha, NE 68131, USA \\ ${ }^{2}$ Department of Communication Sciences and Disorders, College of Allied Health Sciences East Carolina University, Greenville, \\ NC 27858, USA \\ ${ }^{3}$ Department of Ophthalmology and Visual Sciences, University of Nebraska Medical Center, Omaha, NE 68198, USA
}

Received: 21 September 2007; Accepted: 29 February 2008; Online publication: 6 May 2008

\begin{abstract}
Unlike the structural and mechanical role of bone crystals, the inertial mass of otoconia crystals provides a shearing force to stimulate the mechanoreceptors of the utricle and saccule (the gravity receptor organ) under the stimuli of linear motion. It is not clear whether otoconia, composed primarily of $\mathrm{CaCO}_{3}$ and glycoproteins, go through similar calcification processes as bone. We have recently shown that otoconin90 (Oc90) regulates the growth of otoconia crystals as osteopontin does bone crystals. Here, we analyzed the role of this non-collagenous bone matrix protein, osteopontin, in otoconia formation and balance function utilizing its knockout mice, whose inner ear phenotype has not been examined. Despite the presence of the protein in wild-type otoconia and vestibular hair cells, morphological, ultrastructural, and protein and calcium composition analyses of osteopontin null otoconia show that the protein is not needed for crystal formation, and no evidence of compensatory protein deposition is found. Employment of a wide spectrum of balance behavioral tests demonstrates that the protein is not critical for balance function either, which is confirmed by the normal function of the gravity receptor organ directly measured with linear vestibular-evoked potentials (VsEPs). When compared with findings on other otoconins, the data manifest a hierarchy of importance of proteins in crystallization and indicate
\end{abstract}

Correspondence to: Yunxia Wang Lundberg - Genetics Department · Boys Town National Research Hospital · Omaha, NE 68131, USA. Telephone: +1-402-4986735; fax: +1-402-4986351; email: lundbergy@ boystown.org mechanistic similarities and differences between bone and otoconia calcification.

Keywords: balance behaviors, calcification, vestibular-evoked potentials, bone

\section{INTRODUCTION}

In humans, otoconia and other vestibular disorders are prevalent and severely interfere with daily life. It is estimated that $50 \%$ of those at age 65 years or older will develop positional vertigo, whose most common cause is otoconia dislocation. Otoconia degeneration and abnormalities worsen with exposure to ototoxic drugs, infection of the vestibular labyrinth, certain genetic mutations, and in the elderly (Preston et al. 1975; Ross et al. 1976; Lim 1984; Zhang et al. 1996; Balsamo et al. 2000), although accurate statistics are not available. To develop effective treatments, it is imperative to identify the necessary and sufficient components for crystal regeneration or prevention of degeneration.

We have recently demonstrated that, during the formative stage, otoconia matrix particles (the organic framework upon which inorganic $\mathrm{CaCO}_{3}$ crystals are deposited) and crystals exhibit a striking ultrastructural resemblance to bone matrix vesicles and crystals, respectively, (Zhao et al. 2007) despite the fact that bone crystals contain calcium phosphate (apatite), and otoconia crystals contain calcium carbonate (calcite). Furthermore, the organic components of otoconia are either the same or belong to the same family of bone matrix proteins. Both types of matrices 
contain sulfated glycosaminoglycans (as GAGs or proteoglycans), osteopontin (OPN), fetuin-A, and members of the collagen $\mathrm{X}$ family (collagen $\mathrm{X}$ in bone and otolin in otoconia; Lundberg et al. 2006; Zhao et al. 2007). The fourth known otoconia component protein, Oc90, is the predominant otoconial matrix protein (Wang et al. 1998; Verpy et al. 1999) whose role in bone formation has yet to be studied.

Of the few otoconial proteins that are also present in bone, OPN is a non-collagenous bone matrix protein involved in ossification. Similar to the essential role of Oc90 in forming the otoconia matrix and regulating crystal growth (Zhao et al. 2007), OPN limits bone crystal sizes and mineral content (Boskey et al. 1993; Hunter et al. 1994; Shapses et al. 2003). In the vestibule, OPN is detected in otoconia and expressed in vestibular hair cells, dark cells, and the endolymph sac (Takemura et al. 1994; Sakagami 2000). The gene is expressed in a number of nervous tissues including the hindbrain, cerebellum, brainstem, spinal cord, and some parts of the peripheral nervous system (Mark et al. 1988; Shin et al. 1999; Ichikawa et al. 2000; Ju et al. 2000; Lee et al. 2001; Marsh et al. 2007). The neuronal phenotype of OPN null mice has not been thoroughly examined, but the lung, heart and kidney of mutant mice show increased fibrosis and apoptosis (Ophascharoensuk et al. 1999; Berman et al. 2004; Zohar et al. 2004). The inner ear phenotype of the null mice has not been examined either. In this study, we analyzed the function of OPN in otoconia calcification utilizing OPN knockout mice that are maintained as $S p p 1$ (secreted phosphoprotein 1, the current official name for OPN). Our working hypothesis is that otoconia component proteins (collectively called otoconins) regulate crystal growth and morphology. Establishment of a mechanistic link between bone and otoconia calcification will greatly benefit studies of otoconia development and vestibular cell biology due to the availability of a wealth of data on bone biology.

\section{MATERIALS AND METHODS}

\section{Mice and histology}

Osteopontin null (as $\mathrm{OPN}^{\mathrm{spp} 1}$ ) mice were obtained from The Jackson Laboratory (Bar Harbor, ME, USA) and maintained in the C57BL/6J (as C57) genetic background by the supplier. Some experiments also included the otoconia-deficient strain Otopetrin $1^{\text {tl }}$ (as Otop $1^{\text {tlt }}$ ) that are known to show imbalance behaviors (Ornitz et al. 1998; Jones et al. 2004; Zhao et al. 2008). The Otop $1^{\text {tlt }}$ mice were also maintained in the $\mathrm{C} 57$ genetic background by The Jackson Laboratory.
The mice were maintained by homozygous inbreeding in the laboratory. Unless otherwise indicated, the acronyms $\mathrm{OPN}^{\mathrm{spp} 1}$ and Otop $1^{\text {tlt }}$ refer to homozygous mutants throughout the report. Animals were euthanized by $\mathrm{CO}_{2}$ asphyxiation before tissue harvesting, and all animal procedures were approved by the Institutional Animal Care and Use Committee at the Boys Town National Research Hospital in accordance with federal guidelines.

For histological examination, inner ears were dissected and fixed in paraformaldehyde (4\%). After decalcification in 0.1 M EDTA ( $\mathrm{pH} 7.4$ ) overnight, tissues were embedded in paraffin for sectioning at $6 \mu \mathrm{m}$.

\section{Alizarin red complexone staining}

To visualize the degree of otoconia calcification, fixed whole-mount vestibular tissues were stained with 1:50 dilutions [(in phosphate buffered saline (PBS)] of $0.5 \%$ alizarin red complexone (ARC; Sigma, St. Louis, MO, USA), a reagent that stains calcium deposits, for $2 \mathrm{~h}$ or overnight at room temperature. After washing off excess staining reagents, tissues were viewed using a Zeiss LSM 510 confocal microscope.

\section{Phalloidin staining}

Fixed and decalcified vestibules were permeabilized with $0.1 \%$ Triton X-100 in PBS for $30 \mathrm{~min}$, washed with PBS and stained with a $50 \mu \mathrm{g} / \mathrm{ml}$ FITC-conjugated phalloidin solution (Sigma) for $40 \mathrm{~min}$ at room temperature. Unbound conjugated phalloidin was washed off with PBS, and tissues were viewed using a Zeiss LSM 510 confocal microscope.

\section{Scanning electron microscopy}

Animals were anesthetized using a sublethal dose of ketamine $(167 \mathrm{mg} / \mathrm{kg}$ ) and xylazine $(2 \mathrm{mg} / \mathrm{kg})$, perfused through the left ventricle with artificial endolymph (125 mM KCl, $25 \mathrm{mM} \mathrm{KHCO}_{3}, 5 \mathrm{mM}$ HEPES, $2 \mathrm{mM} \mathrm{CaCl}_{2}, 1 \mathrm{mM} \mathrm{NaCl}$ ), followed by 20-30 $\mathrm{ml} 4 \%$ paraformaldehyde $+2.5 \%$ glutaraldehyde $+3 \mathrm{mM} \mathrm{CaCl} 2$ in $0.1 \mathrm{M}$ sodium cacodylate ( $\mathrm{pH}$ 7.2). Utricles and saccules were dissected out of the inner ear in the fixative, and openings were made by gently breaking the bony capsules at the "roof" of the utricle and saccule. Tissues were immersion-fixed for $24 \mathrm{~h}$ in the same fixative, washed three times with artificial endolymph, and postfixed in $1 \%$ osmium tetroxide in $0.1 \mathrm{M}$ sodium cacodylate $(\mathrm{pH} 7.2)$ for $1 \mathrm{~h}$. Samples were then dehydrated, critical point dried in $\mathrm{CO}_{2}$, mounted, sputter coated with gold palladium, and viewed on a Jeol (JSM-848) scanning electron microscope (SEM) at $15 \mathrm{kV}$. 


\section{Otoconia dissection and protein assays}

A detailed description of crystal dissection and stringent washes to clean off the filaments and membranes was provided previously (Zhao et al. 2007). The crystals were decalcified, and proteins were extracted with $10 \mu \mathrm{l}$ of buffer (40 mM Tris, 4\% CHAPS (3-[(3-cholamidopropyl) dimethylammonio]-1-propanesulfonate), $8 \mathrm{M}$ urea, $10 \mathrm{mg} / \mathrm{ml}$ dithiothreitol (DTT), $0.15 \mathrm{M} \mathrm{EDTA)} \mathrm{at} 4^{\circ} \mathrm{C}$ overnight. The buffer was used to dissolve any EDTAinsoluble component of otoconia crystals as was reported for fish otoliths (Murayama et al. 2004). After removal of EDTA and salts using a Centricon column (Millipore, Billerica, MA, USA), protein concentrations and total protein contents were determined using a MicroBCA (bicinchoninic acid) Protein Assay Kit (Pierce, Rockford, IL, USA) following the manufacturer's protocol. Briefly, $100 \mu \mathrm{l}$ of each diluted bovine serum albumin standards and protein samples were added into microplate wells; $100 \mu \mathrm{l}$ of freshly prepared working reagent (A:B:C at 25:24:1) was added into each well and mixed gently. The reaction was incubated at $37^{\circ} \mathrm{C}$ for $2 \mathrm{~h}$ with rocking, and the absorbance was measured at $562 \mathrm{~nm}$ on a Quant MQX200 plate reader (Bio-Tek Instruments, Inc. Winooski, VT, USA). Protein concentrations were calculated according to standard curves.

\section{Western blotting}

Extraction of otoconial proteins and determination of protein concentrations were carried out in the same way as above. An aliquot of each sample containing an equal amount of total protein was mixed with $2 \times$ sample loading buffer (0.13 M Tris-HCl, 20\% glycerol, $46 \mathrm{mg} / \mathrm{ml}$ sodium dodecyl sulfate (SDS), $0.2 \mathrm{mg} / \mathrm{ml}$ bromophenol blue, $20 \mathrm{mg} / \mathrm{ml}$ DTT), boiled for $5 \mathrm{~min}$, loaded onto a 4-15\% gradient Tris-SDS gel (Bio-Rad, Hercules, CA, USA), electrophoresed at $200 \mathrm{~V}$ in running buffer (25 mM Tris $\mathrm{pH} 8.3,192 \mathrm{mM}$ glycine, $0.1 \%$ SDS) for $2 \mathrm{~h}$, and transferred to a PVDF membrane (Millipore) at $100 \mathrm{~V}$ for $1 \mathrm{~h}$. The blot was washed once with Tris buffer containing salt and Tween (TBST) (50 mM Tris, $150 \mathrm{mM} \mathrm{NaCl}, 0.1 \%$ Tween-20) and treated with 3\% blocking buffer (Roche Applied Science, Indianapolis, IN, USA) overnight at room temperature. The membrane was incubated with an antibody against the N-terminal 15 amino acids of Oc90 (Zhao et al. 2007) at 1:1,000 dilution for $3 \mathrm{~h}$ followed by three washes in TBST buffer and incubated with a peroxidaseconjugated goat anti-rabbit IgG secondary antibody (1:10,000; Sigma) for another $3 \mathrm{~h}$. After three washes, detection solution was added for $1 \mathrm{~min}$, and the blot was exposed to a Kodak X-ray film. Blots were imaged using the Canoscan 8400F imaging station, and protein band intensities were analyzed using the Image software (http://rsb.info.nih.gov/ij/).

\section{Ratiometric calcium measurement}

Otoconia crystals were dissected, and $\mathrm{CaCO}_{3}$ was dissolved in $0.05 \mathrm{~N} \mathrm{HCl}$. Serial dilutions $(150 \times-$ $200 \times$ ) in $\mathrm{Ca}^{2+}$-free calibration buffer were made for neutralization and quantification purposes and $\left[\mathrm{Ca}^{2+}\right]$ was measured using the ratiometric dye, Fura-2 (Molecular Probes, Eugene, OR, USA). After adding Fura-2 $(100 \mu \mathrm{M})$, an aliquot of test solution was placed in a sealed glass pipette and imaged using a cooled CCD camera (SensiCam, Cooke Corp., La Jolla, CA, USA) on an upright fixed stage microscope (Nikon E600FN, Garden City, NY, USA). Axon Imaging Workbench (AIW 2.2, Axon Instruments) was used to control the camera, filter wheel (Lambda 10-2, Sutter Instruments, Novato, CA, USA), and image acquisition. $\left[\mathrm{Ca}^{2+}\right]$ was calculated from the ratio of light emitted at $510 \mathrm{~nm}$ during alternate excitation by 340 and $380 \mathrm{~nm}$ light (Grynkiewicz et al. 1985). Calibration constants (standard curve) were determined using a series of highly buffered $\mathrm{Ca}^{2+}$ test solutions (Molecular Probes), and $\mathrm{Ca}^{2+}$ concentrations in the resolved otoconia were determined using the standard curve.

\section{Tests for imbalance behaviors}

The following complementary tests are commonly used to detect balance deficits manifested in postural control, spatial orientation, and sensorimotor function and coordination (Trune and Lim 1983; Sondag et al. 1995, 1996, 1998, 1999; Ying et al. 1999; Jones et al. 2004; Walton et al. 2005; Rampello and Drago 1999; Hamm 2001; Sajdel-Sulkowska et al. 2005). Severe abnormalities in the gravity receptor organ often lead to abnormal air-righting reflexes, irregular and wider gaits, compromised ability to swim, or shortened stay on the rotorod (Trune and Lim 1983; Ying et al. 1999; Rampello and Drago 1999; Hamm 2001; Jones et al. 2004). Details of the methods are described in Zhao et al. 2008 and are briefly summarized below. We assessed the grip strengths of the animals to rule out neuromuscular weakness as a possible secondary outcome of the vestibular sensory deficits. Furthermore, we directly measured the input to the peripheral gravity receptor organ using vestibular evoked potential (VsEP) recordings. The age, genotype, and number of mice tested are summarized in the corresponding tables presented in the "Results" section.

The air-righting reflex was tested on pups three times in a row on each day from P9 to P11. The position with which the pups landed and the time they took to right their body positions were recorded. Reaching response was recorded by observing the reaction of the limbs and head-bobbing behaviors 
when animals were suspended by their tails. Animals that extend their forelimbs and try to reach a surface are normal, whereas animals with vestibular deficits either clasp their forelimbs or have head-bobbing behavior. Both adults (2-6 months old) and pups (23 weeks old) were tested. Regularity of animals' gaits was observed on a white paper after applying India ink to the paws. The stride length and width were compared between null and age-matched C57 controls using previously published methods (Klapdor et al. 1997; Clarke and Still 1999) and adapted from a standard protocol used by the Charles River Laboratories (Wilmington, MA, USA). Findings with P20 pups are reported in this paper.

\section{Swimming test}

Swimming behavior of adult mice (2-6 months old) was observed for 15-30 s. The test was repeated three times on different days, and the following scoring system was used: 0 , the animal was totally submerged, could not maintain orientation at the surface of the water, and required immediate rescue. 1 , the animal could swim to the surface if submerged, but did not maintain a horizontal body line at the surface and may re-submerge briefly. 2 , the animal stayed at the surface but hesitated for a few seconds before swimming almost normally. 3, the animal swam at the surface immediately and maintained horizontal body position at the surface. Due to some ambiguity of scores 2 and 3, we categorized the mice as poor (score 0 ), intermediate (score 1 ), or good swimmers (score 2 and 3 ).

\section{Rotorod test}

Adult animals between the ages of 2-6 months old were placed on a 2-cm-diameter stationary and then on a rotating rod (Rotamex-5, Columbus Instruments, Columbus, OH, USA). The rotation was initially set at a constant speed of $5 \mathrm{rpm} / \mathrm{min}$ as a test run. Once each mouse was able to maintain balance for $1 \mathrm{~min}$ in each trial, it was then tested on the accelerating rod (5-20 rpm over $3 \mathrm{~min}$ ) for three consecutive trials per day for four consecutive days. At the end of each trial, animals that stayed on the rod were left on until they fell. A laser sensor detected if the animal fell from the rod, and the time and speed of rotation at falling were recorded. The average time the mice remained on the rotorod (mean latency) was calculated from five to eight animals and plotted for each trial, each genotype, and each age group. The mean values of all mice in one genotype were compared with those of C57 controls in the same trial using Student's $t$ test assuming similar variances. All tests were carried out within the same time window of the day (between 2 and 4 P.M.) to control for possible variations introduced by circadian rhythms.

\section{Beam-crossing}

A round wood bar of $2.5 \mathrm{~cm}$ in diameter was attached to two Styrofoam platforms at the ends, and the length of the bar to be crossed is adjustable at the ends. Before the test, adult mice (2-6 months old) were fasted for a maximum of $4 \mathrm{~h}$ (water was provided ad libitum) to use food (rodent chow) as an effective incentive for the animals to cross the beam. Pretraining of mice on the bar at $5 \mathrm{~cm}$ long was performed first, followed by three trials of crossing the bar at $30 \mathrm{~cm}$ long in a row. As wild-type (wt) mice often paused on the beam to explore at some point, time spent in crossing the bar at $30 \mathrm{~cm}$ was not used for quantitative purposes. Rather, the posture (i.e., lowered body position) and behavior (i.e., reluctance, nervousness) on the beam were observed.

\section{Grip-strength test}

Mutant and control mice were made to hang in a supine position on an inverted metal meshwork, and the length of time the animal remained on the meshwork was recorded.

\section{Data analysis}

Data are presented as mean \pm standard deviation (SD) where applicable. Balance behaviors (except rotorod tests) of mutant strains were compared to C57 controls using Chi-square analysis. Latencies before falling off the rotorod were compared as described above. $P$ values less than 0.05 were considered statistically significant.

\section{Measurement of vestibular-evoked potentials}

\section{Animal preparation}

The use of animals for vestibular-evoked potentials (VsEPs) was also approved at East Carolina University. Mice were anesthetized with a ketamine $(120 \mathrm{mg} / \mathrm{kg})$ and xylazine $(13 \mathrm{mg} / \mathrm{kg})$ solution, and core body temperature was maintained at $37.0 \pm 0.1{ }^{\circ} \mathrm{C}$ using a homeothermic heating blanket system (FHC, Inc.). VsEPs were measured from 5-month-old mice.

\section{Vestibular stimulus coupling and recording parameters}

VsEP recording procedures followed methods previously published (Jones et al. 1999, 2002, 2004; Jones and Jones 1999). Herein, we used a noninvasive method (a spring clip) to couple the head to the voltage-controlled mechanical shaker that delivered the motion stimuli. Linear acceleration pulses (17 pulses/s, $2 \mathrm{~ms}$ duration) were presented to the cranium in the naso-occipital axis using two stimulus polarities, normal and inverted. Stimulus amplitude 
ranged from $+6 \mathrm{~dB}$ to $-18 \mathrm{~dB}$ re: $1.0 \mathrm{~g} / \mathrm{ms}$ (where $1 \mathrm{~g}=$ $9.8 \mathrm{~m} / \mathrm{s}^{2}$ ) adjusted in $3 \mathrm{~dB}$ steps.

Ongoing electroencephalographic activity was amplified $(200,000 \times)$, filtered ( 300 to $3,000 \mathrm{~Hz},-6 \mathrm{~dB}$ amplitude points), and digitized (1,024 points, $10 \mu \mathrm{s} / \mathrm{pt}$ ). Primary responses, 256, were averaged and replicated for each VsEP waveform. VsEP recordings began at the maximum stimulus intensity (i.e., $+6 \mathrm{~dB}$ re: $1.0 \mathrm{~g} / \mathrm{ms}$ ) with and without acoustic masking (broadband forward masker 50 to $50,000 \mathrm{~Hz}$ at $97 \mathrm{~dB}$ SPL), then intensity was dropped to $-18 \mathrm{~dB}$ and raised in $3 \mathrm{~dB}$ steps to complete an intensity profile. The masker was used to verify absence of cochlear responses (Jones and Jones 1999).

\section{Data analysis}

The first positive and negative response peaks were scored for VsEPs, as this initial response peak is generated by the peripheral eighth nerve. Peak latencies (measured in milliseconds, ms), peakto-peak amplitude (measured in microvolts, $\mu \mathrm{V}$ ) and thresholds (measured in $\mathrm{dB}$ re: $1.0 \mathrm{~g} / \mathrm{ms}$ ) were quantified. Descriptive statistics were generated, and independent sample $t$ test was used to compare VsEP response parameters between $\mathrm{OPN}^{\mathrm{spp} 1}$ and $\mathrm{C} 57$ mice.

\section{RESULTS}

Osteopontin is not required for otoconia formation

The similar effects of Oc90 and OPN on crystal formation suggest that OPN may regulate otoconia calcification. In the present study, we tested this hypothesis by analyzing the otoconia phenotype of the OPN ${ }^{\text {sppl }}$ null mice. Deletion of OPN protein in the null mice was previously validated (Liaw et al. 1998) and was confirmed in the present study by Western blotting of otoconia extracts (data not shown). With Oc90 comprising nearly $90 \%$ of the otoconial protein content (Pote and Ross 1986; Wang et al. 1998; Ornitz et al. 1998), OPN is present at only a low level in wt otoconia (Takemura et al. 1994; Sakagami 2000; Zhao et al. 2007).

No abnormality was found in the overall appearance of the end organ of the OPN ${ }^{\text {spp1 }}$ null mice. Shown in Figure 1 is hematoxylin-and-eosin (H\&E)stained $6 \mu \mathrm{m}$ sections of the utricule and saccule. All structures, including hair/supporting cells and the otoconia layer, were apparently normal. SEM observation of otoconia crystals revealed normal sizes and morphology when compared to those of C57 mice (Fig. 2A, B and Table 1). Averaged measurements of lengths and midsection widths are shown in Table 1. There was no significant difference in the averaged measurements of lengths $\times$ widths of otoconia crystals



FIG. 1. No abnormality is found in the morphology of the otoconia layer and the vestibule of OPN ${ }^{\text {spp } 1}$ mice. H\&E-stained paraffinembedded sections $(6 \mu \mathrm{m})$ are shown. The OPN ${ }^{\mathrm{spp} 1}$ otoconia layer has normal thickness and staining pattern for H\&E (B\&D) as compared to that in the C57 control (A\&C). G Gelatinous layer, $O$ otoconia, $O M$ otoconial membrane, $M$ macula (including hair/supporting cells).

in representative areas sampled in $\mathrm{C} 57$ and $\mathrm{OPN}^{\mathrm{spp} 1}$ mice: above the peripheral utricular macula, above the central utricular macula, and all over the saccule. Similar to those in C57 mice, the saccular otoconia of the $\mathrm{OPN}^{\mathrm{spp} 1}$ mice were more homogeneous in sizes and were much smaller than the utricular ones. The ratio of length versus width was about 2:1 for both utricular and saccular crystals in both strains of mice. Unlike the Oc90 null mice (Zhao et al. 2007), there was no reduction in the otoconial membranes $(\mathrm{OM})$ of the $\mathrm{OPN}^{\mathrm{spp} 1}$ utricle and saccule (Fig. 2C, D). In Figure $2 \mathrm{C}$ and $\mathrm{D}$, the whole-mount tissues were partially decalcified to expose some parts of the $\mathrm{OM}$ for observation and at the same time to leave some overlying crystals to minimize mechanic tearing of the $\mathrm{OM}$. Only the $\mathrm{OM}$ of the striola region is shown in the figure. $\mathrm{OM}$ in the peripheral region of the utricle and saccule of the $\mathrm{OPN}^{\mathrm{spp} 1}$ vestibule has smaller holes than the striola region, similar to those in C57 (data not shown). Staining of inorganic $\mathrm{CaCO}_{3}$ deposits with ARC showed similar degrees of otoconia calcification in the $\mathrm{OPN}^{\mathrm{spp} 1}$ and $\mathrm{C} 57$ mice (Fig. 2E, F), which was confirmed by fura- 2 ratiometric $\mathrm{Ca}^{2+}$ measurements of equal masses $(0.24 \mathrm{mg})$ of otoconia dissolved in equal volumes of $0.05 \mathrm{~N} \mathrm{HCl}(10 \mu \mathrm{l} \mathrm{each}$; Fig. 3A). In Figure 3A, the $\mathrm{Ca}^{2+}$ concentrations were similar between $\mathrm{OPN}^{\mathrm{spp} 1}$ and C57 mice $(p=0.4)$. 

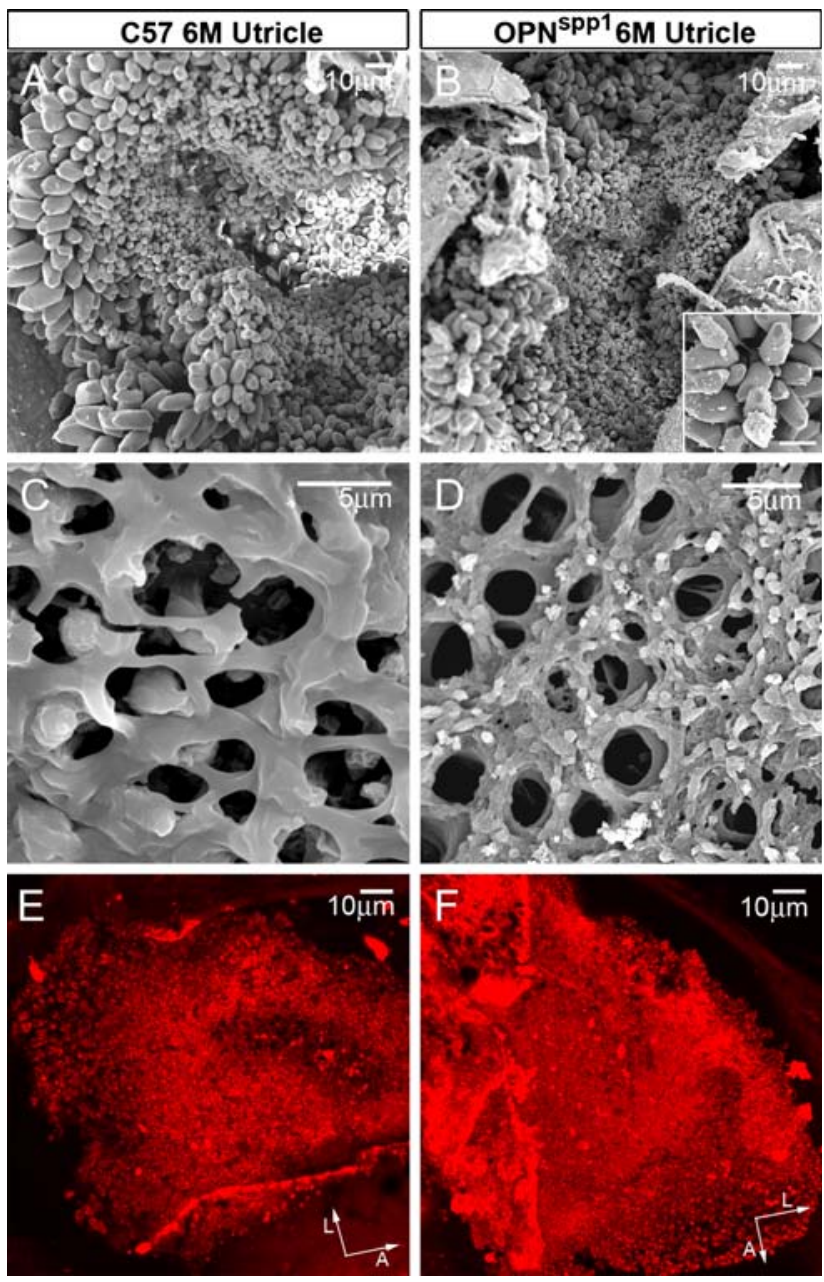

FIG. 2. A, B OPN $\mathrm{N}^{\text {spp } 1}$ otoconia have normal morphology and sizes as demonstrated by SEM. Detailed size measurements are presented in Table 1. The inset provides a closer view of the peripheral crystals in (B). The scale bar in the inset is also $10 \mu \mathrm{m}$. C, D SEM of partially decalcified tissues shows normal otoconia membrane in the OPN ${ }^{\text {spp1 }}$ null utricle and saccule (the utricle is shown). E, $\mathbf{F}$ Normal degree of otoconia calcification in the OPN ${ }^{\text {spp } 1}$ null mice as demonstrated by staining of inorganic calcium deposits with Alizarin Red Complexone. Quantitative ratiometric $\mathrm{Ca}^{2+}$ measurements are presented in Figure 3 .

To identify potential compensatory events, if any, that may have led to the normal otoconia phenotype, we analyzed the total protein content and composition of $\mathrm{OPN}^{\mathrm{spp} 1}$ null otoconia (1 month old). The null crystals contained $4.5 \pm 0.52 \mu \mathrm{g}$ total protein $/ \mathrm{mg}$ otoconia mass, compared to $4.2 \pm 0.65 \mu \mathrm{g}$ total protein/mg otoconia mass for age-matched C57 otoconia $(p=0.40, n=4)$ (Fig. 3A). Western blotting of protein extracts from $\mathrm{OPN}^{\mathrm{spp} 1}$ and $\mathrm{C} 57$ otoconia showed similar levels of Oc90 (Fig. 3B; $p>0.05$ ). The $p$ value was obtained by the Student's $t$ test of the products of the intensity (pixels) $\times$ area of Oc90 bands of null and control blots. The small difference in the total protein loaded in the gel $(3.9 \mu \mathrm{g}$ for C57 and $4.2 \mu \mathrm{g}$ for
$\mathrm{OPN}^{\mathrm{spp} 1}$ ) was taken into account in the calculation. The migratory property of Oc90 was also unaltered in the null mice, suggesting normal posttranslational modification. The unmodified theoretical mass of secreted murine Oc90 is $50 \mathrm{kDa}$, and the size of the predominant glycosylated form is approximately $80 \mathrm{kDa}$ (Ignatova et al. 2004; Zhao et al. 2007). These unchanged measurements exclude significant deposition of ectopic compensatory proteins that are normally foreign to otoconia. Although the data do not directly exclude possible deposition of another compensatory minor protein, the increased mineral content in bone crystals of OPN nulls argues against such a possibility (Boskey et al. 1993; Hunter et al. 1994; Shapses et al. 2003). Thus, OPN is not likely to play a significant role in otoconia morphogenesis or calcification. It is possible that the protein may not be an integral part of otoconia but only adheres to the crystals, which is also suggested by its presence in Oc90 null otoconia that lack any organic matrix (Zhao et al. 2007).

Osteopontin is not critical for the morphogenesis or function of the gravity receptor organ

Next, we examined the vestibular morphology and ultrastructure of $\mathrm{OPN}^{\mathrm{spp} 1}$ null mice to gain insight into the role of the protein in vestibular development and function. In addition to the normal utricular and saccular structures shown in Figure 1, the density and organization of hair cells and stereocilia were similar between the null and C57 utricle and saccule, as visualized by phalloidin-staining of hair bundles in decalcified whole-mount tissues (Fig. 4). High magnification SEM showed no abnormality in hair bundle sizes or organization in the $\mathrm{OPN}^{\mathrm{spp} 1}$ vestibule (insets in Fig. 4). Thus, absence of OPN does not affect the morphological development of the gravity receptor organ.

Given the expression patterns of OPN in vestibular hair cells and other nervous tissues, the OPN ${ }^{\text {spp1 }} 1$ mice

\section{TABLE 1}

Normal sizes of OPN ${ }^{\text {spp } 1}$ otoconia compared to those of $\mathrm{C} 57$ mice (6-month-old animals sampled, $n=16$ )

\begin{tabular}{llcc}
\hline \multicolumn{1}{c}{ Genotype } & & Length $(\mu \mathrm{m})$ & Width $(\mu \mathrm{m})$ \\
\hline Peripheral utricle & C57 & $14.5 \pm 2.8$ & $7.3 \pm 1.6$ \\
& OPN $^{\text {spp1 }}$ & $13.0 \pm 2.1$ & $7.3 \pm 1.0$ \\
Central utricle & C57 $^{\text {spp1 }}$ & $4.2 \pm 1.0$ & $2.6 \pm 0.3$ \\
Saccule & OPN $^{\text {spp }}$ & $4.3 \pm 0.7$ & $2.4 \pm 0.3$ \\
& C57 $^{\text {spp1 }}$ & $2.0 \pm 0.3$ & $1.1 \pm 0.1$ \\
& OPN $^{\text {OPp }}$ & $1.8 \pm 0.4$ & $1.0 \pm 0.1$ \\
\hline
\end{tabular}

There are no significant differences in the lengths $\times$ widths of C57 and $\mathrm{OPN}^{\mathrm{spp} 1}$ utricular or saccular otoconia

OPN Osteopontin 

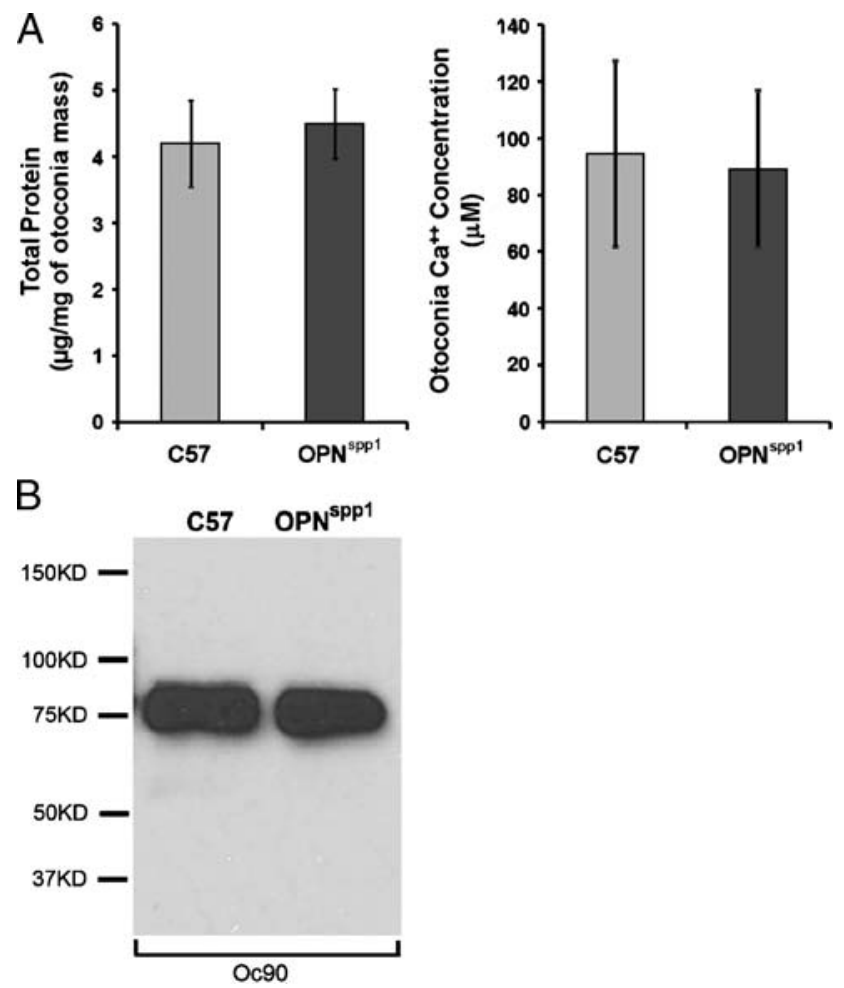

FIG. 3. A The total protein content and calcium concentration are similar between $\mathrm{C} 57$ and OPN ${ }^{\text {spp } 1}$ null otoconia $(p>0.05, n=4 ; p>$ $0.05, n=8$ respectively). The calcium concentrations are compared with equal volume $(10 \mu \mathrm{l})$ and equal mass $(0.24 \mathrm{mg})$ of dissolved otoconia. B The level of the predominant otoconial protein, Oc90, is similar in equal masses of $\mathrm{C} 57$ and $\mathrm{OPN} \mathrm{N}^{\mathrm{spp} 1}$ null otoconia. Analysis of protein band intensities $\times$ areas showed no significant difference between $\mathrm{C} 57$ and OPN ${ }^{\text {spp1 }}$.

may have molecular deficits in the sensory cells, ganglia, or other nervous tissues despite the unaffected morphology. Such deficits may lead to imbalance of the animals. We performed a series of balance tests to test this hypothesis. Several issues may make it difficult to pinpoint the source of balance deficits, if any, in the null mice. First of all, behavioral tests assess coordinated functions of the peripheral and central nervous systems (PNS and CNS) and the neuromuscular system. Potential effects, if any, of OPN deletion on the nervous system are likely diverse, with both beneficial and adverse outcomes (see "Discussion" section for more details). In addition, mild deficits may elude detection due to behavioral adaptation. Nevertheless, when interpreted with other types of data including reports of CNS and PNS analyses of the mice, the wide spectrum of balance tests performed on a number of mice should provide an indication of vestibular function despite the limitation of each test alone.

$\mathrm{OPN}^{\mathrm{spp} 1}$ null pups showed normal development of the air-righting reflex (Table 2). Between P9-11, null mice, like their C57 controls, could instantly right their body positions $(<0.8 \mathrm{~s}$ on average at $\mathrm{P} 9)$ and land in an upright position when held by their tails and suspended to make a backward somersault. In comparison, $91-100 \%$ of Otop $1^{\text {tlt }}$ mice often landed in a supine position rather than the normal prone position and took $>3 \mathrm{~s}$ on average to right their body positions. All the OPN ${ }^{\mathrm{spp} 1}$ null pups and adults had normal reaching responses (Table 2), posture, and gaits (Fig. 5A, B). The mice manifested no unusual home cage behavior, nor did they circle, tilt their heads, move slowly, or become confused. All the $\mathrm{OPN}^{\mathrm{spp} 1}$ mice swam normally (score 3 ; Table 2) and crossed the beam just like the controls. The mice had normal grip strengths as well, indicating an absence of neuromuscular weakness.

In addition, the $\mathrm{OPN}^{\mathrm{spp} 1}$ mice performed well on the rotorod (Fig. 5C): The latencies of their stay on the accelerating rotorod had no significant differences compared to those for age-matched C57 controls on all days (day $1-4 ; p>0.05,2-6$ months old). In contrast, age-matched Otop $1^{\text {tlt }}$ mice stayed on two to three times shorter than either $\mathrm{C} 57$ mice or OPN ${ }^{\text {spp } 1}$ $(p<0.05$; Zhao et al. 2008). Like the C57 mice, the $\mathrm{OPN}^{\mathrm{spp} 1}$ mice demonstrated remarkable learned behavioral adaptation of vestibular functions and stayed longer with the progressing of each trial. There was a nearly fourfold increase in latencies on the rotorod on day 4 compared to day $1 \quad(p<0.001)$, demonstrating normal synaptic potentiation of vestibular neurons, proprioceptors, or locomotor control centers. Although central compensation can potentially mask peripheral deficits (Rampello and Drago 1999; Dubois et al. 2002; Besson et al. 2005; Bothe et al. 2005), concurrent tests with otoconia mutants show that the learned improvement actually differentiates further the normal and imbalance behaviors because the mutants improved less after training (Zhao et al.
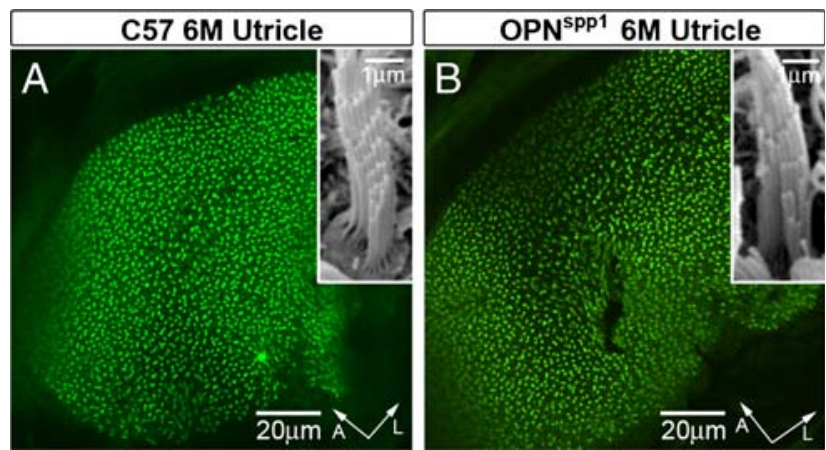

FIG. 4. No abnormality is found in the density, organization, and appearance of stereocilia in the adult vestibule of OPN ${ }^{\text {spp1 }}$ null mice. Phalloidin-stained whole-mount utricles of $\mathrm{OPN}^{\mathrm{spp} 1}$ (B) and C57 mice (A) and SEM of utricular hair bundles (insets) are shown. Arrows indicate orientation of whole-mount tissues ( $A$ Anterior, $L$ lateral). 
TABLE 2

$\mathrm{OPN}^{\text {spp1 }}$ null mice show normal balance behaviors

\begin{tabular}{llll}
\hline \multicolumn{1}{c}{ Abnormal/total } & C57 & Otop ${ }^{\text {tt }}$ & OPN \\
\hline Head-tilting (2-3 weeks) & $0 / 12$ & $10 / 12^{*}$ & $0 / 11$ \\
Head-tilting (adult) & $0 / 12$ & $7 / 10^{*}$ & $0 / 8$ \\
Air-righting (P9-10) & $0 / 10$ & $9 / 9^{*}$ & $0 / 8$ \\
Reaching (2-3 weeks) & $0 / 10$ & $12 / 12^{*}$ & $0 / 11$ \\
Reaching (adult) & $0 / 12$ & $7 / 10^{*}$ & $0 / 8$ \\
Swimming (adult) & $0 / 14$ & $6 / 8^{*}$ & $0 / 8$ \\
\hline
\end{tabular}

The number of mice showing imbalance behaviors is shown as numerators and the total number of mice tested as denominators. The Otop $1^{\text {tlt }}$ mice are known to have imbalance behaviors (Ornitz et al. 1998; Jones et al. 2004 Zhao et al. 2008) and are included here as a comparison. Adult ages tested were 2-6 months old. Poor and intermediate swimmers were counted as abnormal.

Otop1 Otopetrin 1, OPN osteopontin

*Denotes significant difference $(p<0.05)$ compared to C57 balance behaviors using Chi-square analysis
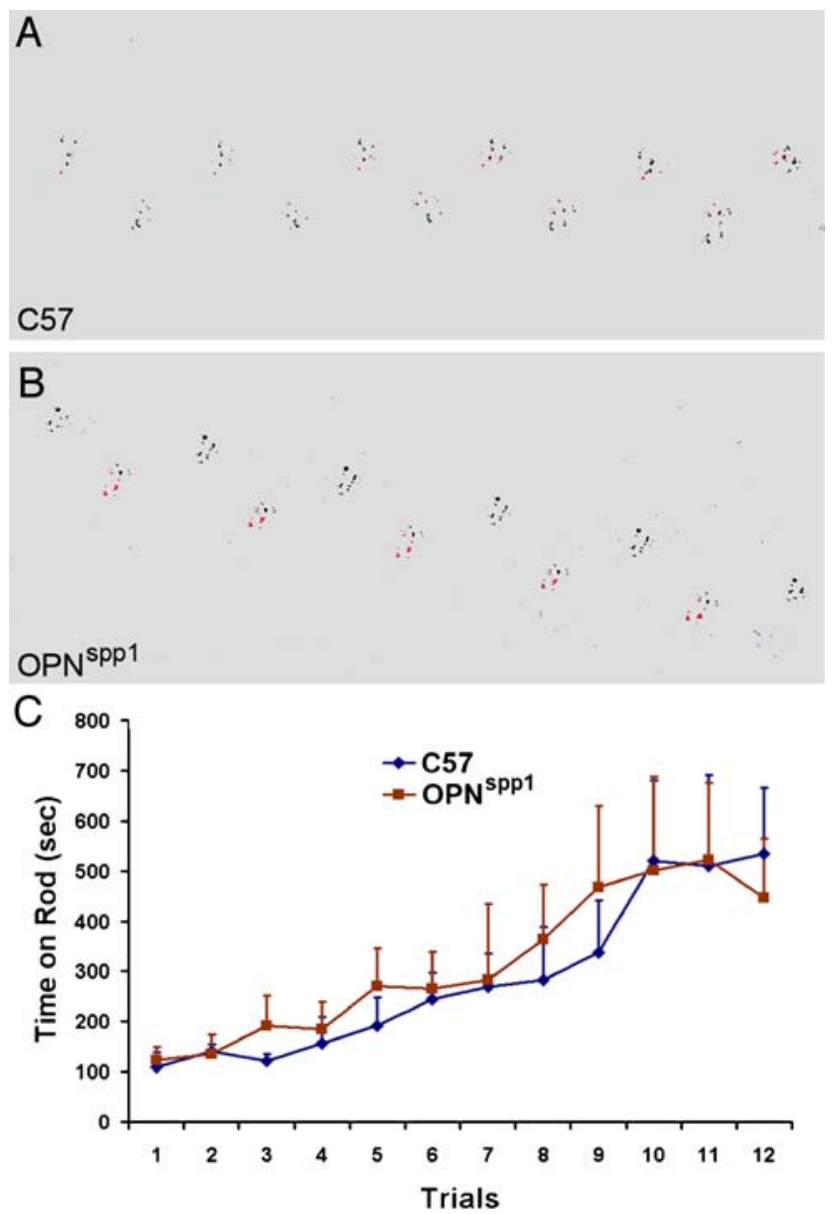

FIG. 5. Normal balance behaviors of $O P N^{\text {spp1 }}$ null mice. Statistical comparisons are listed in Table 2. OPN ${ }^{\text {spp1 }}$ null mice have normal gaits B compared to $\mathbf{C} 57 \mathrm{Bl} / 6$ mice $\mathbf{A}$. C The latencies on the accelerating rod are similar for $\mathrm{OPN}^{\text {spp1 }}$ null mice $(n=8)$ and agematched C57 mice ( $n=5,2-6$ months old). Error bars represent SDs.
2008). Furthermore, the normal balance behaviors are consistent with the normal morphology and ultrastructure of otoconia and vestibular sensory epithelia. Therefore, OPN is not critical for balance functions.

To confirm the conclusion from behavioral assessments, we directly measured the afferent function of the gravity receptor organ under the stimuli of linear motion. Figure 6A shows VsEP thresholds for OPN ${ }^{\text {spp1 }}$ null and $\mathrm{C} 57$ control mice. On average, $\mathrm{OPN}^{\mathrm{spp} 1}$ mice had VsEP thresholds similar to the controls $(-9.5 \pm$ $3.1 \mathrm{~dB}$ re: $1.0 \mathrm{~g} / \mathrm{ms}$ for $\mathrm{OPN}^{\mathrm{spp} 1},-9.7 \pm 2.1 \mathrm{~dB}$ re: $1.0 \mathrm{~g} / \mathrm{ms}$ for $\mathrm{C} 57)$. VsEP response peak amplitudes (data not shown) and latencies (Fig. 6B) were also similar between the two strains of mice. Therefore, absence of OPN does not alter the sensory input or the functional status of the gravity receptor organ.

\section{DISCUSSION}

Despite the prevalence of otoconia-related balance problems in humans, the underlying molecular etiology is completely unknown. In recent years, a number of otoconins have been identified, but the roles of most of these proteins in crystal formation remain unclear. Dissecting the importance of each otoconial protein in otoconia development will help in designing rational treatments for otoconial lesion and for prevention and regeneration purposes.

The absence of any changes in the ultrastructure, protein and calcium content of $\mathrm{OPN}^{\mathrm{spp} 1}$ null otoconia strongly suggests that the protein is not critical for otoconia formation and that compensation by another unidentified factor is unlikely. The normal balance behaviors, morphology and ultrastructure of the null utricle and saccule indicate that the protein is also not
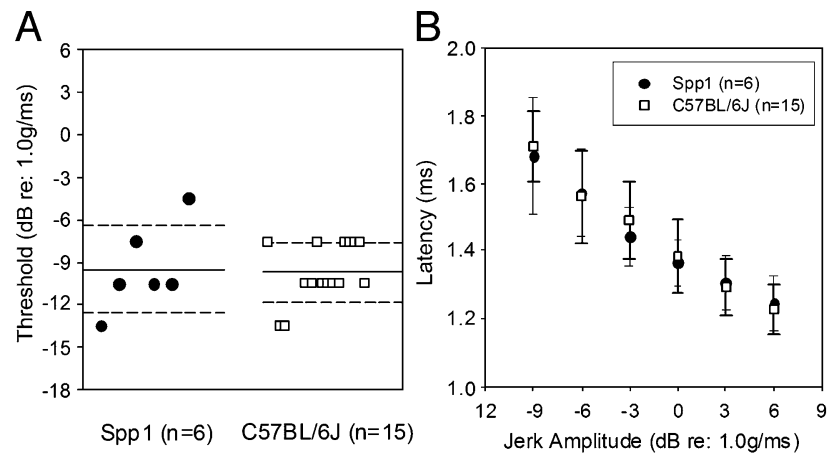

FIG. 6. A Similar VsEP thresholds for OPN ${ }^{\text {spp1 }}$ null (as Spp1) and C57 control mice. Solid horizontal lines represent the mean for each group and the dashed lines represent 1 SD above and below the mean. B Mean VsEP latencies for response peak P1 (generated by the peripheral vestibular nerve) as a function of stimulus amplitude. Error bars represent SDs. On average, response peak latencies for OPN ${ }^{\text {spp } 1}$ mice are similar to controls. 
critical for the morphogenesis or function of the gravity receptor organ, which is confirmed by the presence of normal VsEPs.

Both Oc90 and OPN are non-collagenous matrix proteins that, together with collagen, form the organic framework upon which the inorganic crystals are deposited (Rana-Chavez and Nanci 2001; Laboux et al. 2003; Zhao et al. 2007). Both limit the growth of the mineral crystals, but neither is involved in the initial mineral accretion (Shapses et al. 2003; Zhao et al. 2007). The effect of OPN on bone mineral deposition is a combination of a direct involvement of the protein as a hydroxyapatite-binding matrix protein and as a signaling molecule that recruits osteoclasts (Shapses et al. 2003). Oc90 is required to form the otoconia matrix by specifically recruiting other matrix components (Zhao et al. 2007). It has not been examined whether Oc90 has other indirect effects on otoconia formation.

Interestingly, OPN and Oc90 are co-expressed in vestibular dark cells and the endolymphatic sac, with the onset of Oc90 expression being much earlier than that for OPN (Verpy et al. 1999; Sakagami 2000; Ignatova et al. 2004). Given the negligible role of OPN in otoconia formation, such cellular co-localization may be coincidental or may merely reflect cellular activities in secretion and/or ion fluxes, two processes that may provide some components for otoconia formation or maintain homeostasis of the endolymph. A calcium pump, plasma membrane-bound calcium ATPase (PMCA2), is also expressed in dark cells, in addition to hair cells, and mice with mutant PMCA2 have absent otoconia (Kozel et al. 1998). Unlike the bone environment, $\mathrm{Ca}^{2+}$ concentration in the endolymph is low. The $\mathrm{Ca}^{2+}$-binding otoconial proteins and sulfated GAGs may be co-secreted with $\mathrm{Ca}^{2+}$ or may sequester $\mathrm{Ca}^{2+}$ and efficiently raise the local $\mathrm{Ca}^{2+}$ level in the matrix and/or in the otoconial membranes for calcification. As the functions of these molecules in $\mathrm{Ca}^{2+}$-sequestration may be redundant, it is possible that deletion of a minor component like OPN is buffered by other multiple components without the need to increase their expression levels.

It is not clear what kind of effect OPN may have on sensorimotor neurons. The potential impact (if any) of OPN on the CNS and PNS to affect balance and coordination likely involve both positive and negative effects. At the cellular level, the protein has proadhesive, chemotactic and cytokine-like properties, and is involved in a number of physiologic and pathologic events including angiogenesis, apoptosis, inflammation, oxidative stress, remyelination, wound healing, bone remodeling, cell migration and tumorigenesis (Chakraborty et al. 2006; El-Tanani et al. 2006; Pagano and Haurani 2006). As some of these events lead to neurodegeneration (Maetzler et al.
2007; Wung et al. 2007) whereas others to neuroprotection (Meller et al. 2005; Schroeter et al. 2006), the overall outcome in sensorimotor neurons may have been neutralized in the null deletion.

In summary, we demonstrate that OPN is not critical for otoconia formation or balance functions. When interpreted with previous findings, the data show a hierarchy of importance of otoconins in crystallization. Given the critical role of OPN in bone crystal growth, the present study indicates molecular differences between otoconia and bone calcification.

\section{ACKNOWLEDGEMENTS}

Part of the work was supported by grants from the National Institute on Deafness and Other Communication Disorders (DC008603 to YWL and DC006443 to SMJ) and the National Center for Research Resources (1P20RR018788 to YWL). The content is solely the responsibility of the authors and does not necessarily represent the official views of the National Institute on Deafness and Other Communication Disorders or the National Institutes of Health.

\section{REFERENCES}

Balsamo G, Avallone B, Del GF, Trapani S, Marmo F. Calcification processes in the chick otoconia and calcium binding proteins: patterns of tetracycline incorporation and calbindin-D28K distribution. Hear Res. 148:1-8, 2000.

Berman JS, Serlin D, Li X, Whitley G, Hayes J, Rishikof DC, Ricupero DA, Liaw L, Goetschkes M, O’Regan AW. Altered bleomycininduced lung fibrosis in osteopontin-deficient mice. Am. J. Physiol Lung Cell Mol. Physiol. 286:L1311-L1318, 2004.

Besson V, Nalesso V, Herpin A, Bizot JC, Messaddeq N, Romand R, Puech A, Blanquet V, Herault Y. Training and aging modulate the loss-of-balance phenotype observed in a new ENU-induced allele of Otopetrin1. Biol. Cell. 97:787-798, 2005.

Boskey AL, Maresca M, Ullrich W, Doty SB, Butler WT, Prince CW. Osteopontin-hydroxyapatite interactions in vitro: inhibition of hydroxyapatite formation and growth in a gelatin-gel. Bone Miner. 22:147-159, 1993.

Bothe GW, Bolivar VJ, Vedder MJ, Geistfeld JG. Behavioral differences among fourteen inbred mouse strains commonly used as disease models. Comp. Med. 55:326-334, 2005.

Chakraborty G, Jain S, Behera R, Ahmed M, Sharma P, Kumar V, Kundu GC. The multifaceted roles of osteopontin in cell signaling, tumor progression and angiogenesis. Curr. Mol. Med. 6:819-830, 2006.

Clarke KA, Still J. Gait analysis in the mouse. Physiol Behav. 66:723-729, 1999.

Dubois M, Strazielle C, Eyer J, Lalonde R. Sensorimotor functions in transgenic mice expressing the neurofilament/heavy-LacZ fusion protein on two genetic backgrounds. Neuroscience. 112:447-454, 2002.

El-Tanani MK, Campbell FC, Kurisetty V, Jin D, McCann M, Rudland PS. The regulation and role of osteopontin in malignant transformation and cancer. Cytokine Growth Factor Rev. 17:463-474, 2006.

Grynkiewicz G, Poenie M, Tsien RY. A new generation of $\mathrm{Ca}^{2+}$ indicators with greatly improved fluorescence properties. J. Biol. Chem. 260:3440-3450, 1985. 
Hамм RJ. Neurobehavioral assessment of outcome following traumatic brain injury in rats: an evaluation of selected measures. J. Neurotrauma. 18:1207-1216, 2001.

Hunter GK, Kyle CL, Goldberg HA. Modulation of crystal formation by bone phosphoproteins: structural specificity of the osteopontin-mediated inhibition of hydroxyapatite formation. Biochem. J. 300 (Pt 3):723-728, 1994.

Ichikawa H, Itota T, Nishitani Y, Tori Y, Inoue K, Sugimoto T. Osteopontin-immunoreactive primary sensory neurons in the rat spinal and trigeminal nervous systems. Brain Res. 863:276-281, 2000.

Ignatova EG, Thalmann I, Xu B, Ornitz DM, Thalmann R. Molecular mechanisms underlying ectopic otoconia-like particles in the endolymphatic sac of embryonic mice. Hear Res. 194:65-72, 2004.

JoNES TA, JoNES SM. Short latency compound action potentials from mammalian gravity receptor organs. Hear Res. 136:75-85, 1999.

Jones SM, Erway LC, Bergstrom RA, Schimenti JC, Jones TA. Vestibular responses to linear acceleration are absent in otoconia-deficient C57BL/6JEi-het mice. Hear Res. 135:56-60, 1999.

Jones SM, Subramanian G, Avniel W, Guo Y, Burkard RF, Jones TA. Stimulus and recording variables and their effects on mammalian vestibular evoked potentials. J. Neurosci. Methods. 118:2331, 2002.

Jones SM, ERWAY LC, Johnson KR, Yu H, Jones TA. Gravity receptor function in mice with graded otoconial deficiencies. Hear Res. 191:34-40, 2004.

Ju WK, Кim KY, Сha JH, Kim IB, Lee MY, OH SJ, Chung JW, Chun MH. Ganglion cells of the rat retina show osteopontin-like immunoreactivity. Brain Res. 852:217-220, 2000.

Klapdor K, Dulfer BG, Hammann A, Van der StaAy FJ. A low-cost method to analyse footprint patterns. J. Neurosci. Methods. 75:49-54, 1997.

Kozel PJ, Friedman RA, Erway LC, Yamoah EN, Liu LH, Riddle T, Duffy JJ, Doetschman T, Miller Ml, Cardell El, Shull GE. Balance and hearing deficits in mice with a null mutation in the gene encoding plasma membrane $\mathrm{Ca}^{2+}$-ATPase isoform 2. J. Biol. Chem. 273:18693-18696, 1998.

Laboux O, Ste-Marie LG, Glorieux FH, Nanci A. Quantitative immunogold labeling of bone sialoprotein and osteopontin in methylmethacrylate-embedded rat bone. J. Histochem. Cytochem. 51:61-67, 2003.

Lee MY, Choi JS, Lim SW, Cha JH, Chun MH, Chung JW. Expression of osteopontin mRNA in developing rat brainstem and cerebellum. Cell Tissue Res. 306:179-185, 2001.

Liaw L, Birk DE, Ballas CB, Whitsitt JS, Davidson JM, Hogan BL. Altered wound healing in mice lacking a functional osteopontin gene (spp1). J. Clin. Invest. 101:1468-1478, 1998.

Lim DJ. Otoconia in health and disease. A review. Ann. Otol. Rhinol. Laryngol. 112(Suppl):17-24, 1984.

Lundberg YW, Zhao X, Yamoah EN. Assembly of the otoconia complex to the macular sensory epithelium of the vestibule. Brain Res. 1091:47-57, 2006.

Maetzler W, Berg D, Schalamberidze N, Melms A, Schott K, Mueller JC, Liaw L, Gasser T, Nitsch C. Osteopontin is elevated in Parkinson's disease and its absence leads to reduced neurodegeneration in the MPTP model. Neurobiol. Dis. 25:473-482, 2007.

Mark MP, Prince CW, Gay S, Austin RL, Butler WT. 44-kDal bone phosphoprotein (osteopontin) antigenicity at ectopic sites in newborn rats: kidney and nervous tissues. Cell Tissue Res. 251:23-30, 1988.

Marsh BC, Kerr NC, Isles N, Denhardt DT, Wynick D. Osteopontin expression and function within the dorsal root ganglion. Neuroreport. 18:153-157, 2007.

Meller R, Stevens SL, Minami M, Cameron JA, King S, Rosenzweig H, Doyle K, Lessov NS, Simon RP, Stenzel-Poore MP. Neuroprotec- tion by osteopontin in stroke. J. Cereb. Blood Flow Metab. 25:217-225, 2005.

Murayama E, Takagi Y, Nagasawa H. Immunohistochemical localization of two otolith matrix proteins in the otolith and inner ear of the rainbow trout, Oncorhynchus mykiss: comparative aspects between the adult inner ear and embryonic otocysts. Histochem Cell Biol. 121:155-166, 2004.

Ophascharoensuk V, Giachelli CM, Gordon K, Hughes J, Pichler R, Brown P, Liaw L, Schmidt R, Shankland SJ, Alpers CE, Couser WG, Johnson RJ. Obstructive uropathy in the mouse: role of osteopontin in interstitial fibrosis and apoptosis. Kidney Int. 56:571-580, 1999.

Ornitz DM, Bohne BA, Thalmann I, Harding GW, Thalmann R. Otoconial agenesis in tilted mutant mice. Hear Res. 122:60-70, 1998.

Pagano PJ, Haurani MJ. Vascular cell locomotion: osteopontin, NADPH oxidase, and matrix metalloproteinase-9. Circ. Res. 98:1453-1455, 2006.

Pоте KG, Ross MD. Ultrastructural morphology and protein content of the internal organic material of rat otoconia. J. Ultrastruct. Mol. Struct. Res. 95:61-70, 1986.

Preston RE, Johnsson LG, Hill JH, Schacht J. Incorporation of radioactive calcium into otolithic membranes and middle ear ossicles of the gerbil. Acta Otolaryngol. 80:269-275, 1975.

Rampello L, Drago F. Nicergoline facilitates vestibular compensation in aged male rats with unilateral labyrinthectomy. Neurosci. Lett. 267:93-96, 1999.

RANA-ChavEZ VE, NANCI A. High-resolution immunocytochemistry of noncollagenous matrix proteins in rat mandibles processed with microwave irradiation. J. Histochem. Cytochem. 49:1099-1109, 2001.

Ross MD, Peacor D, Johnsson LG, Allard LF. Observations on normal and degenerating human otoconia. Ann. Otol. Rhinol. Laryngol. 85:310-326, 1976.

Sajdel-Sulkowska EM, Nguon K, Sulkowski ZL, Rosen GD, Baxter MG. Purkinje cell loss accompanies motor impairment in rats developing at altered gravity. Neuroreport. 16:2037-2040, 2005.

SAKAGAMI M. Role of osteopontin in the rodent inner ear as revealed by in situ hybridization. Med. Electron Microsc. 33:3-10, 2000.

Schroeter M, Zickler P, Denhardt DT, Hartung HP, Jander S. Increased thalamic neurodegeneration following ischaemic cortical stroke in osteopontin-deficient mice. Brain. 129:1426-1437, 2006.

Shapses SA, Cifuentes M, Spevak L, Chowdhury H, Brittingham J, Boskey AL, Denhardt DT. Osteopontin facilitates bone resorption, decreasing bone mineral crystallinity and content during calcium deficiency. Calcif. Tissue Int. 73:86-92, 2003.

Shin SL, Cha JH, Chun MH, Chung JW, Lee MY. Expression of osteopontin mRNA in the adult rat brain. Neurosci. Lett. 273:73-76, 1999.

Sondag HN, de Jong HA, van MJ, Oosterveld WJ. Effects of sustained acceleration on the morphological properties of otoconia in hamsters. Acta Otolaryngol. 115:227-230, 1995.

Sondag HN, de Jong HA, van MJ, Willekens B, Oosterveld WJ. Otoconial alterations after embryonic development in hypergravity. Brain Res. Bull. 40:353-356, 1996.

Sondag HN, de Jong HA, van MJ, Oosterveld WJ. Behavioural changes in hamsters with otoconial malformations. Acta Otolaryngol. 118:86-89, 1998.

Sondag HN, de Jong HA, Oosterveld WJ. Behaviour of adult hamsters subjected to hypergravity. J. Vestib. Res. 9:13-18, 1999.

Takemura T, Sakagami M, Nakase T, Kubo T, Kitamura Y, Nomura S. Localization of osteopontin in the otoconial organs of adult rats. Hear Res. 79:99-104, 1994.

TRUNe DR, LIM DJ. The behavior and vestibular nuclear morphology of otoconia-deficient pallid mutant mice. J. Neurogenet. 1:5369, 1983. 
Verpy E, Leibovici M, Petit C. Characterization of otoconin-95, the major protein of murine otoconia, provides insights into the formation of these inner ear biominerals. Proc. Natl. Acad. Sci. U. S. A. 96:529-534, 1999.

Walton KD, Benavides L, Singh N, Hatoum N. Long-term effects of microgravity on the swimming behaviour of young rats. J. Physiol. 565:609-626, 2005.

Wang Y, Kowalski PE, Thalmann I, Ornitz DM, Mager DL, Thalmann R. Otoconin-90, the mammalian otoconial matrix protein, contains two domains of homology to secretory phospholipase A2. Proc. Natl. Acad. Sci. U. S. A. 95:15345-15350, 1998.

Wung JK, Perry G, Kowalski A, Harris PL, Bishop GM, Trivedi MA, Johnson SC, Smith MA, Denhardt DT, Atwood CS. Increased expression of the remodeling- and tumorigenic-associated factor osteopontin in pyramidal neurons of the Alzheimer's disease brain. Curr. Alzheimer Res. 4:67-72, 2007.
Ying HC, Hurle B, Wang Y, Bohne BA, Wuerffel MK, Ornitz DM. High-resolution mapping of tlt, a mouse mutant lacking otoconia. Mamm. Genome. 10:544-548, 1999.

Zhang DM, Takumida M, Harada Y. Uptake of tetracycline in otoconia of the guinea pig. Acta Otolaryngol. 116:732-736, 1996.

Zhao X, Jones SM, Yamoah EN, Lundberg YW. Oc90 deletion leads to imbalance but normal hearing: a comparison with other otoconia mutants. Neuroscience. 153:289-299, 2008.

Zhao X, Yang H, Yamoah EN, Lundberg YW. Gene targeting reveals the role of Oc90 as the essential organizer of the otoconial organic matrix. Dev. Biol. 304:508-524, 2007.

Zohar R, Zhu B, Liu P, Sodek J, McCulloch CA. Increased cell death in osteopontin-deficient cardiac fibroblasts occurs by a caspase3-independent pathway. Am. J. Physiol Heart Circ. Physiol. 287: H1730-H1739, 2004. 